\section{Regional anaesthesia in high-risk infants}

\section{To the Editor:}

We were impressed with the number of problems reported by Webster $e t$ al., in their experience providing spinal anaesthesia for high-risk neonates. ${ }^{1}$ Also we have encountered some complications and reviewed our experience over a four-year period.

We attempted to perform spinal anaesthesia for inguinal hernia repair in 62 expremature infants with a mean weight of $2.9 \mathrm{~kg}$ and a mean postconceptual age of $42 \mathrm{wk}$. Tetracaine with epinephrine was used for all patients, usually in a dose of $0.4 \mathrm{mg} \cdot \mathrm{kg}^{-1}$ and a minimum of $1 \mathrm{mg}$. Placement of the block was done in the lateral decubitus position.

We were unable to locate CSF in six patients. In four infants the sensory level achieved was inadequate to perform the procedure, and general anaesthesia was required. In two infants, the sensory level was sufficient to repair the symptomatic hernia, but it receded too quickly to allow exploration of the asymptomatic side. Two infants developed respiratory insufficiency associated with high segmental blocks and required tracheal intubation. Two infants developed hypotension shortly after the block was placed which responded to fluid boluses. One infant with no preoperative history of apnoea and who received no sedation had apnoeic episodes intraoperatively. Twenty of the infants required some sedation intraoperatively, usually ketamine, but rarely morphine, fentanyl, thiopentone or nitrous oxide. There were no intraoperative respiratory complications in those patients who received sedatives.

Postoperatively, five of the infants had apnoeic episodes within the first $24 \mathrm{hr}$ of surgery. One episode was temporally related to the use of morphine for postoperative analgesia. The other four infants had preoperative histories of apnoea, and had received no sedatives in the perioperative period.

While we believe that regional anaesthesia in this highrisk population is preferable to general anesthesia, we have found that spinal anaesthesia is not without complications. Since reviewing these 62 cases, we discovered that increasing the dosage of tetracaine has provided higher sensory levels and a longer duration of block. The technical problems of the difficult or failed spinal are not so easily rectified. We have found that placing caudals is usually easier and associated with a high success rate. ${ }^{2,3}$ The onset of sensory blockade is slower, and muscle relaxation is not as profound with caudal anaesthesia as with spinal anaesthesia. Despite this, our surgeons have been pleased with the uniformly successful blocks. We now routinely initially attempt caudal blockade using
$0.375 \%$ bupivicaine with 1:200,000 epinephrine unless there is a contraindication.

Ann Bailey MD

Robert Valley MD

John Peacock MD

Department of Anaesthesia

University of North Carolina

Chapel Hill, North Carolina 27514

\section{REFERENCES}

1 Webster AC, McKishnie JD, Kenyon CF, Marshall DG. Spinal anaesthesia for inguinal hernia repair in high-risk neonates. Can J Anaesth 1991; 38: 281-6.

2 Spear RM, Deshpande JK, Maxwell LG. Caudal anesthesia in the awake, high-risk infant. Anesthesiology 1988; 69: 407.

3 Gunter JB, Dunn CM, Bower RJ, Ternberg JL. Caudal epidural anesthesia in sixty-nine conscious premature and high-risk infants. Anesthesiology 1990; 73: A1097.

\section{Extradural blood patch for post-lumbar puncture headaches in cancer patients}

To the Editor:

We were recently asked to evaluate a 19 -yr-old girl who was severely debilitated by a headache $24 \mathrm{hr}$ after diagnostic lumbar puncture. The patient with a diagnosis of embryonal cell rhabdomyosarcoma required a lumbar puncture in accordance with her assigned treatment protocol to survey for evidence of central nervous system involvement. The patient was encouraged by the encologist to increase her oral fluid intake and remain supine. Oral analgesics were not prescribed.

On questioning, the patient stated that the headache followed the assumption of the upright position. This was consistent with the diagnosis of postdural puncture headache (PDPH). The lumbar puncture was done with a 22gauge spinal needle and $15 \mathrm{ml}$ of CSF were removed for evaluation. The patient reported that she was taking no medications other than chemotherapy.

We informed the oncologist of the reported efficacy of the epidural blood patch in relieving PDPH symptoms. ${ }^{1}$ However, we expressed our reservations with regard to performing this procedure in the cancer patient. Specifically, our main concern was the risk of seeding the neuraxis with neoplastic cells. The oncologist shared our concerns but felt that in this patient with a well localized tumour, an extradural blood patch could be offered. 